\title{
Elaboração e caracterização de fermentado probiótico com geléia de uva roxa (Vitis vinífera l)
}

\author{
Elaboration and characteriation of probiotic ferementate with purple grape jelly (Vitis vinúfera l) \\ Elaboración y caracterización de ferementado probiótico com jalea de uva morada (Vitis vinífera l)
}

Recebido: 12/04/2021 | Revisado: 18/04/2021 | Aceito: 27/04/2021 | Publicado: 12/05/2021

Eduarda Josefa Alves Marçal

ORCID: https://orcid.org/0000-0003-0021-9144 Centro Universitário UniFacisa, Brasil E-mail: eduardamarcal826@gmail.com

Joyce Almeida Lima

ORCID: https://orcid.org/0000-0002-5113-1903 Centro Universitário UniFacisa, Brasil

E-mail: joyce.lima@maisunifacisa.com.br

Ana Clara Bezerra Felinto

ORCID: https://orcid.org/0000-0002-5611-6948 Centro Universitário UniFacisa, Brasil E-mail: anaclarabfelinto@gmail.com

Igor Macêdo de Oliveira

ORCID: https://orcid.org/0000-0003-3717-7291 Centro Universitário UniFacisa, Brasil E-mail: igormacedo1955@gmail.com

Juliana Barbosa de Sousa

ORCID: https://orcid.org/0000-0002-2228-8004 Centro Universitário UniFacisa, Brasil

E-mail: juliana.bs628@gmail.com Steffany Albuquerque do Bú

ORCID: https://orcid.org/0000-0002-4804-4657 Centro Universitário UniFacisa, Brasil

E-mail: steffanyalbuquerque12@gmail.com

Wagner Gomes de Melo

ORCID: https://orcid.org/0000-0001-5198-0457 Centro Universitário UniFacisa, Brasil E-mail: wagnerlegionario@hotmail.com

Mayra da Silva Cavalcanti

ORCID: https://orcid.org/0000-0003-1269-5324 Centro Universitário UniFacisa, Brasil

E-mail: mayra_cavallcanti@yahoo.com.br

\begin{abstract}
Resumo
O iogurte é um alimento fermentado por microrganismos característicos. Contém componentes essenciais para a saúde, como vitaminas e minerais, proteína, cálcio, potássio, fósforo, vitaminas B6 e B12. Diante disso, o objetivo desse estudo foi desenvolver e caracterizar fermentados com potencial probiótico adicionado de geleia de uva roxa (Vitis vinífera L). Para tanto, foram elaborados três tipos de iogurtes (S1) fermentado controle composto somente pela cultura starter, (S2) fermentado contendo a cultura starter e a geleia de uva roxa, para a formulação probiótica (S3) foi acrescentado Lactobacillus acidophilus, a cultura starter e a geleia de uva roxa. Os produtos foram avaliados quanto aos parâmetros de umidade, acidez titulável, $\mathrm{pH}$, lipídio, lactose, cinzas, sinérese, como também a contagem de células viáveis da bactéria e a qualidade microbiológica. Foi observado que os iogurtes elaborados atenderam aos requisitos físico-químicos e microbiológicos estabelecidos na legislação brasileira vigente, tendo as bactérias lácticas apresentando valores superiores $10^{7} \mathrm{UFC} / \mathrm{mL}$, e ausência de coliformes totais, presença de bolores e leveduras estando dentro do valor permitido pela legislação. Ao fim, verificou-se que a elaboração de fermentado probiótico com geleia de uva- roxa pode demonstrar uma influência positiva, ressaltando a necessidade de mais análises, na comercialização industrial para produtos lácteos que tenham propriedades funcionais, uma vez que apresenta adequadas características físico-químicas e microbiológicas.
\end{abstract}

Palavras-chave: Análise de alimentos; Iogurte; Alimento funcional.

\section{Abstract}

Yogurt is a food fermented by characteristic microorganisms. Contains essential components for health, such as vitamins and minerals, protein, calcium, potassium, phosphorus, vitamins B6 and B12. Therefore, the objective of this study was to develop and characterize fermented products with probiotic potential added to purple grape jelly (Vitis 
vinífera L). For this purpose, three types of fermented yoghurt (S1) were prepared, composed only of the starter culture, (S2) fermented containing the starter culture and the purple grape jelly. For the probiotic formulation (S3), Lactobacillus acidophilus was added, the starter culture. and the purple grape jelly. The products were evaluated for humidity, titratable acidity, $\mathrm{pH}$, lipid, lactose, ash, syneresis parameters, as well as viable bacterial cell counts and microbiological quality. It was observed that the elaborated yogurts met the physical-chemical and microbiological requirements established in the current Brazilian legislation, with lactic acid bacteria presenting values higher than $107 \mathrm{CFU} / \mathrm{mL}$, and the absence of total coliforms, the presence of molds and yeasts being within the value allowed by the legislation. . At the end, it was verified that the elaboration of probiotic fermented with red grape jelly can demonstrate a positive influence, emphasizing the need for more analyzes, in the industrial commercialization for dairy products that have functional properties, since it presents adequate physical- chemical and microbiological.

Keywords: Food analysis; Yogurt; Functional food.

\begin{abstract}
Resumen
El yogur es un alimento fermentado por microorganismos característicos. Contiene componentes esenciales para la salud, como vitaminas y minerales, proteínas, calcio, potasio, fósforo, vitaminas B6 y B12. Por tanto, el objetivo de este estudio fue desarrollar y caracterizar productos fermentados con potencial probiótico añadido a la mermelada de uva morada (Vitis vinífera L). Para ello se prepararon tres tipos de yogur fermentado (S1), compuesto únicamente por el cultivo iniciador, (S2) fermentado que contiene el cultivo iniciador y la jalea de uva morada. Para la formulación probiótica (S3), se añadió Lactobacillus acidophilus, el cultivo iniciador. y la jalea de uva morada. Los productos fueron evaluados en cuanto a humedad, acidez titulable, pH, lípidos, lactosa, cenizas, parámetros de sinéresis, así como recuentos de células bacterianas viables y calidad microbiológica. Se observó que los yogures elaborados cumplieron con los requisitos físico-químicos y microbiológicos establecidos en la legislación brasileña vigente, presentando las bacterias del ácido láctico valores superiores a $10^{7} \mathrm{UFC} / \mathrm{mL}$, y la ausencia de coliformes totales, la presencia de mohos y levaduras. estando dentro del valor permitido por la legislación. Al final, se verificó que la elaboración de probióticos fermentados con mermelada de uva tinta puede demostrar una influencia positiva, enfatizando la necesidad de más análisis, en la comercialización industrial de productos lácteos que tengan propiedades funcionales, ya que presenta adecuadas físico-químicas y microbiológico.
\end{abstract}

Palabras clave: Análisis de los alimentos; Yogur; Comida funcional.

\title{
1. Introdução
}

A utilização dos alimentos como veículo de promoção do bem-estar e saúde, atuando também como redutor dos riscos de algumas doenças tem aumentado nos últimos anos. Os produtos funcionais são aqueles que fornecem benefícios adicionados aos da alimentação do consumidor, além de suas funções nutricionais, eles servem como fonte de energia e de substrato para formação de células e tecidos, atua na modulação e ativa os processos metabólicos, proposionado melhora da saúde e assim a efetividade do sistema imune e promovendo o bem - estar das pessoas (Palanca et al., 2006).

O leite fermentado é conhecido pelo consumidor de várias formas como gel, líquido viscoso, em diluição, concentrado ou seco. No processo de fabricação o leite fermentado passa pela fase de elaboração preliminar da base de leite, mistura, aquecimento, fermentação, resfriamento, com ou sem adição de fruta, embalagem e acondicionamento sob refrigeração (Tamine et al., 2011). Este alimento também pode ser classificado em diferentes faixas de temperatura de fermentação em sua fabricação, podendo ser mesofílica $\left(20{ }^{\circ} \mathrm{Ca} 30{ }^{\circ} \mathrm{C}\right)$ e termofílica $\left(37^{\circ} \mathrm{Ca} 45^{\circ} \mathrm{C}\right)$, sendo a termofílica a faixa na qual se dá a elaboração de iogurte (Ordóñez et al., 2005).

Os probióticos dentro do intestino competem com microrganismos patogênicos por nutrientes e sítio de ligação nas células epiteliais da mucosa, ajudando na resposta imune do hospedeiro por meio da manutenção da homeostase. Entretanto, os benefícios supramencionados estão relacionados ao tipo da cepa usada (Matsumoto et al., 2012; Hardy et al., 2013).

Os produtos lácteos são difusores importantes para o fornecimento destas cepas aos seres humanos, estando o iogurte entre os mais consumidos em todo o mundo. Assim, é notório o entusiasmo da indústria em sua produção e o crescente número de estudos relacionados ao beneficiamento das cepas probióticas. Ademais, a inclusão destas culturas em produtos lácteos não é capaz de alterar significativamente as propriedades sensoriais (Zeković et al., 2005; Saint-Eve et al., 2006; Burton et al., 2017). 
A maioria dos produtos lácteos disponíveis são produzidos a partir do leite bovino, e utilizam frutas ou geleia de frutas para dar sabor. Todavia, o Brasil oferece uma gama de frutas com sabores e aromas diferenciados, as quais podem ser utilizadas para fazer geleias e assim podem ser uma alternativa para agregar sabor ao iogurte (Borges; Medeiros \& Correia, 2009). A uva é uma das frutas de maior produção mundial, com mais de 67 milhões de toneladas produzidas ao ano. Cultivada principalmente na variedade Vitis vinifera L., sendo a mais utilizada para a produção de vinho (Coimbra; Salvador \& Silva, 2015). Uma fruta rica em compostos fenólicos em elevadas concentrações, o que a faz ser considerada uma fruta antioxidante e rica em propriedades anti-inflamatórias e anticancerígenas (Rockenbach, 2008).

Por conta do aumento da demanda na procura de produtos naturais e suficientemente nutritivos, busca-se sempre inovar o mercado de alimentos com insumos que satisfaçam as demandas do consumidor que a cada dia se encontra cada vez mais exigente. Por isso, nos últimos anos, inúmeros ingredientes foram desenvolvidos e estão sendo usados para enriquecer e melhorar a qualidade de diversos produtos (Silva; Brinques \& Gurak, 2019).

Diante disso, o presente estudo teve como objetivo desenvolver e caracterizar fermentados probióticos com adição de geleia de uva roxa (Vitis vinífera $L$ ), bem como avaliar os parâmetros físico-químicos e microbiológicos.

\section{Metodologia}

A preparação dos fermentados com característica probiótica e da geleia de uva roxa ocorreram no Laboratório de Técnica Dietética, as análises físico-químicas no Laboratório de Bromatologia e Farmacologia e as análises microbiológicas no Laboratório de Microbiologia e Imunologia, todos localizados no Centro Universitário Unifacisa, em Campina Grande - PB.

O leite ultra pausterizado (Betânia®) utilizado foi adquirido em um hipermercado local da cidade de Campina Grande, assim como o açúcar branco do tipo refinado (União®) utilizado para produção do fermentado. No preparo destes utilizaram-se a cultura convencional starter (Christian Hansen®, Minas Gerais, Brasil) composta por Lactobacillus delbrueckii subsp. bulgaricus e Streptococcus salivarius subsp. Thermophillus e a cultura probiótica o Lactobacillus acidophilus (Christian Hansen®, Minas Gerais, Brasil) que foi doada pela professora orientadora.

Foram elaborados três formulações: S1 que corresponde ao fermentado controle composto pela cultura starter; formulação S2, fermentado contendo a cultura starter e a geleia de uva roxa; e a formulação S3, fermentado probiótico elaborado com a cultura starter e o Lactobacillus acidophilus e a geleia de uva roxa. Para facilitar o entendimento as formulações estão descritas na Tabela 1.

Tabela 1 - Formulações Fermentados do Estudo. Campina Grande, PB, Brasil, 2020- 2021.

\begin{tabular}{ccccc}
\hline Formulação & Açúcar & Starter & Geleia & L. Acidophilus \\
\hline S1 & $10 \mathrm{~g}$ & $0,100 \mathrm{~g}$ & - & - \\
S2 & $10 \mathrm{~g}$ & $0,100 \mathrm{~g}$ & $60 \mathrm{~g}$ & - \\
$\mathrm{S} 3$ & $10 \mathrm{~g}$ & $0,100 \mathrm{~g}$ & $60 \mathrm{~g}$ & $0,025 \mathrm{~g}$ \\
\hline
\end{tabular}

Fonte: Autores (2021).

A matéria prima foi homogeneizado com $10 \%$ de açúcar branco do tipo refinado (União®) sendo, posteriormente, submetido ao aquecimento em banho maria, a aferição da temperatura até atingir os $\left(90^{\circ} \mathrm{C}\right)$ foi feita com o uso de um termômetro digital (Benetech - GM 320. Em seguida, procedeu-se o resfriamento em banho de gelo até atingir à temperatura de inoculação (entre $42{ }^{\circ} \mathrm{C}$ e $45{ }^{\circ} \mathrm{C}$ ). Assim, foi acrescido a cultura starter para iniciar o processo de fermentação conjuntamente com o cultivo de Lactobacillus acidophilus, seguindo o descrito na Tabela 1 e as formulações. Em seguida, as 
bebidas foram acondicionadas em recipientes de vidro com a capacidade de $250 \mathrm{ml}$. A fermentação foi feita em estufa (BioBod 120 - $7 \mathrm{Lab}$ ) a $45^{\circ} \mathrm{C}$ por aproximadamente 4 horas. O ponto final da fermentação, e dado através da observação da dureza do coágulo e determinação do $\mathrm{pH}$, que deveria atingir no máximo 4,5 , seguida de resfriamento a $05^{\circ} \mathrm{C}$. A quebra do coágulo foi feita por agitação,com o auxilio de uma colher até consistência homogênea. Sendo por fim, adicionada o preparado de uva roxa, como demostrado na Figura 1.

Figura 1 - Fluxograma para obtenção dos fermentados.

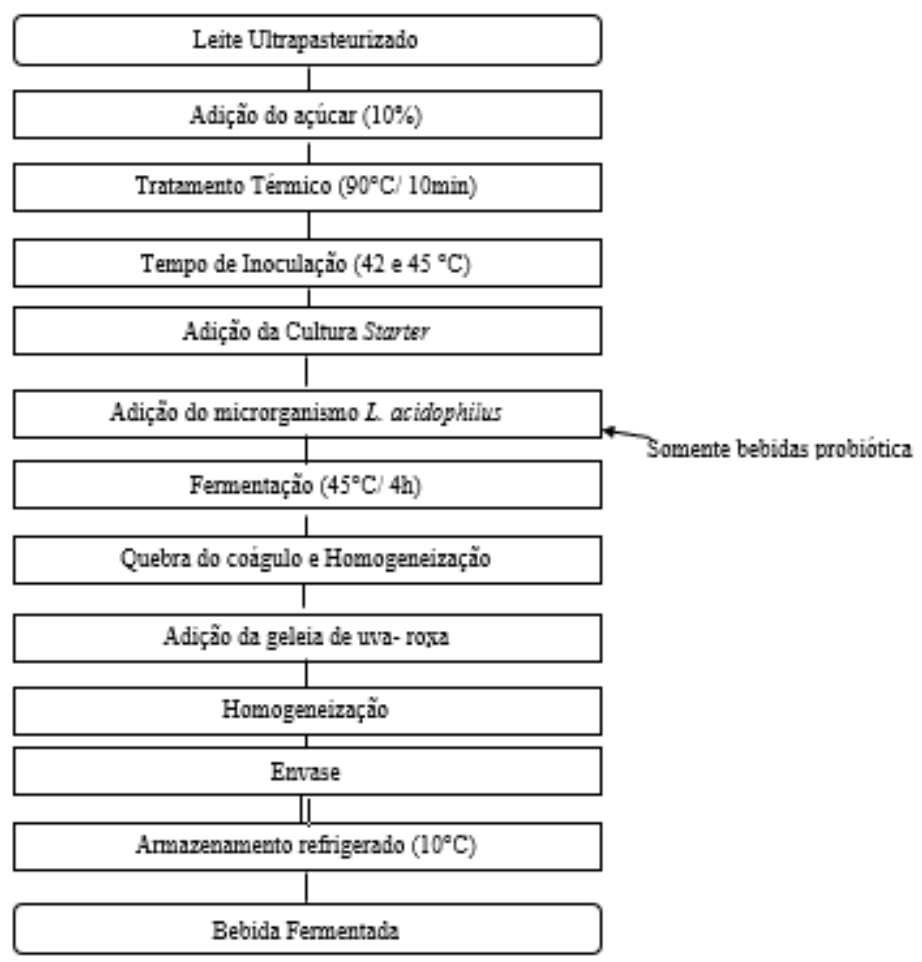

Fonte: Autores (2021).

A geleia extra de uva- roxa (Vitis vinífera $L$.) foi preparada na proporção 50:50 (uva- roxa: açúcar branco refinado) acrescido de um percentual de $10 \%$ do volume de água. As uvas foram higienizadas em água e imergidas em solução clorada por 15 minutos, na diluição de 100 ppm, logo após foram enxaguadas novamente em água corrente. Posteriormente, as uvas foram pulsadas no liquidificador, com o intuito de reduzir a quebra das sementes, com parte da água calculada. O suco foi filtrado com o auxílio de uma peneira de uso caseiro, acrescentado o açúcar e levado ao fogo baixo $\left(180{ }^{\circ} \mathrm{C}\right)$ até que a mesma atingisse $65{ }^{\circ} \mathrm{Brix}$, concernente com a legislação específica, que exige no mínimo $62{ }^{\circ} \mathrm{Brix}$ (BRASIL, 1978). O esquema da preparação da geleia está demostrado na Figura 2. 
Figura 2 - Fluxograma do preparo da geleia de uva.

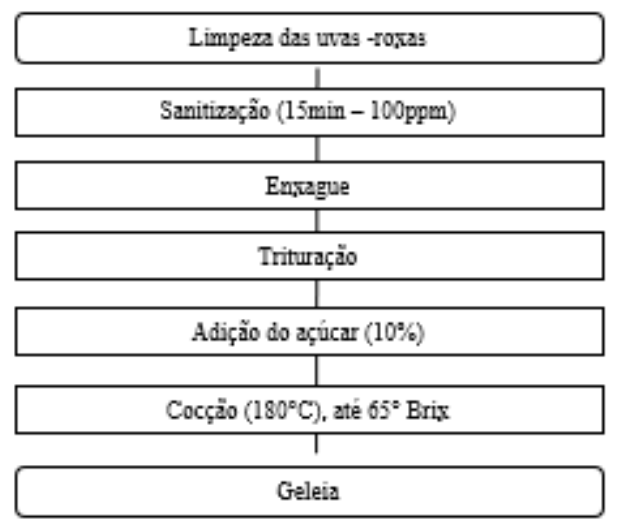

Fonte: Autores (2021).

As amostras foram separadas e estocadas em quantidades iguais para a realização das análises físico-químicas onde foram analisadas: a acidez titulável, o pH, a umidade, as cinzas, a lactose e o teor de lipídeo todas determinadas segundo metodologia descrita pelo Instituto Adolfo Lutz - IAL (2008), com exceção da análise de sinérese que foi testada segundo a metodologia de Riener et al. (2010).

Para a análise de viabilidade celular das bactérias ácido lácticas foi realizada pela metodologia descrita por Association of Official Analytical Chemitis - AOAC (2002). Com interesse de verificar a presença de bolores e leveduras viáveis, foi utilizada a metodologia descrita por Brasil, (2003). Os coliformes totais foram pressupostos pela ultilização da tecnica do número mais provável (NMP) seguindo protocolo descrito pela Instrução Normativa (IN) n ${ }^{\circ} 62$ de 26/08/2003 do Ministério da Agricultura, Pecuária e Abastecimento (MAPA).

Os dados estatísticos referentes as quantificações físico-químicas foram tratados através do programa - Statistics Analys Systems, para o cálculo dos dados, aplicando-se a Análise de Variância (ANOVA) e teste de Tukey, com nível de segurança de 5\%, para confronto das médias (Sas, 1999).

\section{Resultados e Discussão}

Um maior teor de sólidos aumenta a competência de retenção de água das proteínas do leite, prevenindo a sinérese, além de elevar a consistência final do iogurte. $\mathrm{O}$ teor de água tem uma função relevante na qualidade dos alimentos, visto que a umidade elevada é o principal fator para o desencadeamento de alterações de ordem microbiológicas, como a proliferação de fungos, leveduras e bactérias (Stencl; Janstova \& Drackova, 2010).

Amostra S1 difereriu estatisticamente das demais amostras, sendo a S2 e S3 adicionadas da geleia de uva roxa, através dos nossos resultados pode -se observar que a adição da geleia influenciou diretamente na osmolaridade do produto devido a concentração de açucar impactando na diminuição da atividade de água da amostra. Capitani et al. (2014), com iogurtes probióticos e fibras soluvel mostrou resultados de teor de água entre $69,9 \%$ e 75,8 \%, estando bem próximo ao valor encontrado da formulação S1, e superior aos valores das formulações S2 e S3. No estudo de Paiva et al. (2015), com iogurte adicionado de polpa de abacaxi a base de mel, encontrou os valores para este parâmetro entre 76,4 e 79,7 \%. 
Tabela 2 - Valores em média das variáveis físico-químicas do fermentado probiótico com geleia de uva roxa (Vitis vinífera L), Campina Grande, PB, Brasil, 2020 - 2021.

\begin{tabular}{lccc}
\hline \multirow{2}{*}{ VARIAVEIS } & \multicolumn{3}{c}{ FERMENTADO } \\
\cline { 2 - 4 } & S1 & S2 & S3 \\
\hline Umidade $(\mathrm{g} / 100 \mathrm{~g})$ & $81,28 \pm 0,24^{\mathrm{a}}$ & $54,30 \pm 0,43^{\mathrm{c}}$ & $56,56 \pm 0,24^{\mathrm{b}}$ \\
Cinzas $(\mathrm{g} / 100 \mathrm{~g})$ & $0,53 \pm 0,02^{\mathrm{a}}$ & $0,49 \pm 0,01^{\mathrm{a}}$ & $0,52 \pm 0,06^{\mathrm{a}}$ \\
Lactose $(\mathrm{g} / 100 \mathrm{~g})$ & $3,88 \pm 0,01^{\mathrm{c}}$ & $26,20 \pm 0,00^{\mathrm{b}}$ & $30,26 \pm 0,44^{\mathrm{a}}$ \\
Acidez $(\mathrm{g} / 100 \mathrm{~g})$ & $1,59 \pm 0,05^{\mathrm{b}}$ & $2,03 \pm 0,05^{\mathrm{a}}$ & $2,16 \pm 0,05^{\mathrm{a}}$ \\
Lipídeo $(\mathrm{g} / 100 \mathrm{~g})$ & $2,00 \pm 0,00^{\mathrm{a}}$ & $1,00 \pm 0,00^{\mathrm{b}}$ & $1,05 \pm 0,07^{\mathrm{b}}$ \\
pH & $6,68 \pm 0,03^{\mathrm{a}}$ & $6,61 \pm 0,01 \mathrm{ab}$ & $6,60 \pm 0,01^{\mathrm{b}}$ \\
Sinérese & $33,44 \pm 0,40^{\mathrm{a}}$ & $29,95 \pm 0,83^{\mathrm{b}}$ & $30,92 \pm 1,53^{\mathrm{ab}}$ \\
\hline
\end{tabular}

\footnotetext{
${ }^{\mathrm{a}-\mathrm{c}}$ Media \pm desvio-padrão com letras minúsculas diferentes na mesma linha diferiram entre si pelo teste de Tukey $(\mathrm{p}<0,05)$ entre os tratamentos. Fonte: Autores (2021).
}

Quanto aos valores de cinzas, as formulações não apresentaram diferença significativa, o que indica uma manutenção do conteúdo mineral independente das preparações. Esses valores foram inferiores aos reportados por Lima (2011), na elaboração de bebidas fermentadas com polpa de frutas, obtendo valores médios entre 0,63 a 0,66 g/100 g. Nóbrega et al. (2020), encontrou uma variância de 0,61 a $0,75 \mathrm{~g} / 100 \mathrm{~g}$, ou seja, valores superiores aos encontrados neste trabalho (0,55, 0,49 e 0,52). No estudo de Paiva et al. (2015), com iogurte adicionado de polpa de abacaxi a base de mel, foram encontrados valores superiores numa variância de 0,75 a $0,99 \mathrm{~g} / 100 \mathrm{~g}$, visto que, a grande quantidade de minerais contidos no abacaxi e no mel de abelha influenciaram nos resultados.

Quanto aos valores encontrados para lactose é notório que o valor da formulação S1 se diferenciou das outras formulações (S2 e S3), provavelmente essa diferença de valores poderá ter sido pela adição da geleia, haja visto que, a adição do açúcar pode ter poupado a utilização da lactose como substrato para os micro-organismos fermentadores. No trabalho apresentado por Morais (2017), com iogurte caprino o resultado para lactose foi de 3,83 g/100 g, resultado bem semelhante a formulação S1, porém muito inferior do resultado encontrado nos fermentados S2 e S3. No estudo de Nóbrega et al. (2020), com iogurte caprino prebiótico adicionado de geleia de mandacaru e maracujá, apresentou valores inferiores para lactose numa variação de valores entre 9,57 a 14,32 g/100 g. No estudo de Ribeiro (2011), com iogurte probiótico adicionado de Lactobacillus acidóphilus, apresentou valor de 5,26 g/100 g, o que foi superior ao fermentado S1 e bastante inferior aos fermentados S2 e S3 que apresentaram valores 26,20 e 30,26 g/ $100 \mathrm{~g}$.

Segundo a Instrução Normativa $n^{\circ} 46$ de 23 de outubro de 2007, os padrões físico-químicos estabelecidos para leites fermentados, a acidez deve apresentar valores entre 0,6 e 1,5g/100g (Brasil, 2007). Diante ao exposto, as formulações de iogurte fermentado elaboradas nesse estudo não estão em conformidade com os padrões ditados pela Legislação, visto que, a acidez encontrada variou entre 1,59 e $2,16 \mathrm{~g} / 100 \mathrm{~g}$.

No trabalho de Paiva et al. (2015), com iogurte adicionado de polpa de abacaxi a base de mel, a acidez em todas as formulações variou de 0,80 a 0,93 g/100 g, apresentando-se dentro do limite permitido pela legislação. Segundo o estudo de 
Silva et al. (2012), com iogurtes de produção caseira comparados aos industrializados mostrou resultados satisfatório uma variância de 0,75 a 1,08 g/100 g, assim estando dentro do limite preconizado pela legislação.

$O$ teor de gorduras apresentou diferença significativa $(p>0,05)$ entre as amostras, o que chama atenção ao fato de ocorrer uma redução do teor nos produtos adicionado de geleia. Esses resultados se distanciaram do encontrado por Soares (2008), no qual o iogurte apresentou teor de gordura em torno de 3,6 \%. Valores semelhantes a este trabalho foram encontrados no estudo de Cavalcanti (2016), com uma variância de 1,45 a 2,05, ao estudar formulações de fermentados probióticos de leite caprino com adição de geleia de goiaba.

Os valores de lipídios obtidos na presente pesquisa foram inferiores ao preconizado pela resolução vigente (Brasil, 2007), entre 3,0 a 5,9 g/100g de produto. O que pode ser esclarecido pela quebra parcial da gordura que costumeiramente se apresenta no produto, como foi encontrado no estudo realizado por Xanthopoulos, Ipsilandis \&Tzanetakis (2012), em iogurtes com potencial probiótico diferentes.

$\mathrm{O}$ valor de $\mathrm{pH}$ dos fermentados probióticos $\mathrm{S} 1, \mathrm{~S} 2$ e $\mathrm{S} 3$ apresentaram diferenças significativas $(\mathrm{p}>0,05)$ entre eles, sendo o maior valor apresentado pela formulação sem adição de geleia. Sabe-se que as frutas têm pH mais voltado para acidez e isto pode ter influenciado este resultado. Santos (2017), apresentou em seu estudo com iogurte caprino probiótico adicionado de geleia de acerola, valores de $\mathrm{pH}$ nos intervalos de 4,52 a 4,59. Um valor bem inferior ao resultado encontrado no iogurte probiótico com geleia de uva roxa do presente estudo.

De acordo com a Instrução Normativa n 46 de 23 de outubro de 2007, do Ministério da Agricultura Pecuária e Abastecimento, é estabelecido para iogurte $\mathrm{pH}$ desejável com valores maiores que 4,0. Os fermentados produzidos se encontraram dentro dos requisitos mínimos de qualidade, apresentando valores de que variaram entre 6,60 e 6,68. Segundo Franco e Landgraf (2005), alimentos com pH maior que 4,5 sãos mais propícios a multiplicação microbiana, tanto para agentes deteriorantes ou patogênicas.

Em relação a sinérese, as três formulações ( $\mathrm{S} 1, \mathrm{~S} 2$ e S3) apresentaram diferenças significativas ( $\mathrm{p}>0,05)$. Os resultados obtidos podem ser correlacionados a presença da geleia que diminui o teor de sinérese no produto. Valores semelhantes foram encontrados no estudo de Cavalcanti (2016), uma variância entre 16,59 e 33,44. A qualidade do iogurte também está relacionada à separação do soro pelo impacto que esta causa no consumidor pela modificação da textura do alimento. A sinérese é definida pela junção do gel que gera a extrusão de líquido e geralmente ocorre pela reorganização das caseínas ou micelas agrupadas em rede (Lee \& Lucey, 2010).

As análises quanto ao parâmetros higiênico-sanitários das três formulações de fermentados (S1, S2 e S3) com adição de geleia encontram-se adequadas para o consumo humano, uma vez que as contagens de coliformes foram ausentes, e que a presença de bolores e leveduras, concernente com os critérios exigidos pela Legislação Brasileira para este tipo de alimento (Brasil, 2007), indicando que as normas de higiene foram seguidas durante a fabricação do produto. Os resultados encontrados para as análises microbiológicas dos iogurtes foram satisfatórios e estão demonstrados na Tabela 2.

A contaminação microbiana em alimentos pode ocorrer durante qualquer etapa da sua produção, tornando-se um risco à população, quando ocasionam Doenças Transmitidas por Alimentos (DTAs), porém a proliferação de bactérias é frequentemente associada à ausência ou inadequada manipulação, assim como, o tratamento térmico insuficiente (Cohen et al., 2011). Conforme a Tabela 3, o número mais provável (NMP) de coliformes nas amostras S1, S2 e S3 analisadas, encontra- se em conformidade com o padrão estabelecido pela legislação $\left(<10^{2}\right)$. No estudo de Paiva et al. $(2015)$, com iogurte adicionado de polpa de abacaxi, base mel, também encontraram ausência de coliformes. 
Tabela 3 - Contagem de bactérias láticas fermentado do iogurte probiótico com geleia de uva - roxa (Vitis vinífera L). e padrão estabelecido pela legislação para fermentado. Campina Grande, PB, Brasil, 2020 - 2021.

\begin{tabular}{lcccc}
\hline \multirow{2}{*}{ Análises } & \multicolumn{3}{c}{ Fermentado } & Segislação \\
\cline { 2 - 4 } & S1 & S2 & S3 & \\
\hline Bolores e Leveduras (UFC/ml) & 85 & 15 & 5 & $<200$ \\
Coliformes a $45^{\circ} \mathrm{C}(\mathrm{NMP} / \mathrm{ml})$ & ausente & ausente & ausente & $<10^{2}$ \\
Lactobacillus acidóphilus (UFC/ml) & - & - & $1,8 \times 10^{7}$ & $>10^{7}$ \\
Streptococcus thermophilus $(\mathrm{UFC} / \mathrm{ml})$ & $2,9 \times 10^{9}$ & $5,5 \times 10^{8}$ & $2,9 \times 10^{8}$ & $>10^{7}$ \\
\hline
\end{tabular}

* Regulamento Técnico de Identidade e Qualidade de Leites Fermentado (Brasil, 2007).

Fonte: Autores (2021).

Em relação a viabilidade microbiológica do Streptococcus thermophilus, pode-se observar que as três formulações de iogurte (S1, S2 e S3) estão de acordo com os critérios recomendados pela legislação brasileira para fermentados $\left(>10^{7}\right)$, com valores bem superiores ao padrão. No trabalho de Mundim (2008), com iogurte funcional com leite de cabra, saborizado com frutos do cerrado e suplementado com inulina, a contagem de microrganismo tradicional Streptococcus thermophilus se encontrou entre $1,62 \times 10^{9}$ a $5,99 \times 10^{8} \mathrm{UFC} / \mathrm{mL}$ para o iogurte sabor araticum, $1,12 \times 10^{9}$ a 4,98 $\times 10^{8} \mathrm{UFC} / \mathrm{mL}$ para o iogurte sabor cagaita e $1,38 \times 10^{9}$ a $7,90 \times 10^{7} \mathrm{UFC} / \mathrm{mL}$ para o iogurte sabor pequi valores estes superior ao que foi encontrado neste trabalho.

Os Lactobacillus acidóphilus foram bem preservados na amostra S3, visto que os valores encontrados condizem com os critérios recomendados pela legislação. No estudo de Ribeiro (2011), com iogurte probiótico, com contagens para Lactobacillus acidóphilus de 3,02 x 10 10 e 3,60 x 109 UFC/200 g, assim estando de acordo com os critérios exigidos pela legislação e superior aos resultados encontrados neste trabalho.

As formulações produzidas segundo os resultados obtidos para a viabilidade microbiológica das formulações se apresentaram de forma favorável pelos altos valores de micro-organismos presentes. Haja visto que, para ser considerado um alimento probiótico em $100 \mathrm{~g}$ de produtos lácteos devem apresentar pelo menos $10^{6}$ a $10^{7} \mathrm{UFC} / \mathrm{g}$ de cepas probióticas viáveis no momento da compra do alimento e na sua vida de prateleira pela validade (Anvisa, 2007).

\section{Conclusão}

Foi observado que os iogurtes elaborados atenderam a maioria dos requisitos físico-químicos e microbiológicos estabelecidos pela legislação brasileira vigente, com ressalva para a acidez e pH do produto, o que pode favorecer o desenvolvimento de microrganismos. Tendo as bactérias lácticas apresentando valores superiores $10^{7} \mathrm{UFC} / \mathrm{mL}$, e ausência de coliformes totais, presença de bolores e leveduras estando dentro do valor permitido pela legislação. Deixando uma lacuna para estudos aprofundado sobre o produto em suas características de aceitabilidade e tecnológicas, como também traçar o perfil sensorial de aceitação e intenção de compra.

\section{Referências}

Anvisa. (2007). Alimentos com alegações de propriedades funcionais e ou de saúde, novos alimentos/ingredientes, substâncias bioativas e probióticos: lista de alegações de propriedade funcional aprovadas. Agência Nacional de Vigilância Sanitária.

Aoac (2002). Association of Official Analytical Chemistis. Official methods of analysis of AOAC International. Gaithersburg:Association of Official Communities, 1115p. 
Brasil (2003). Instrução Normativa $n^{\circ} 62$ de 26 de agosto de 2003. Métodos analíticos oficiais para análises microbiológicas para controle de produtos de origem animal e água. Brasília: Ministério da agricultura e Pecuária - MAPA.

Brasil (2007). Instrução Normativa N. ${ }^{\circ}$ 46, de 23 de outubro de 2007: Padrões de Identidade e Qualidade (PIQ) de Leites Fermentados. Brasília: Ministério da Agricultura Pecuária e Abastecimento. Departamento de inspeção de produtos de origem animal.

Borges, K. C., Medeiros, A. C. L., Correia, R. T. P. (2009). Buffalos milk yogurt flavored with cajá (Spondias lutea L.) syrup: physical - chemical and sensory acceptance between 11 to 16 year - old individuals. Alimentos e Nutrição, 20 (2), 295-300.

Burton, K. J., Rosikiewicz, M., Pimentel, G., Bütikofer, U., Von AH, U., Voirol, M. J. \& Greub, G (2017). Probiotic yogurt and acidified milk similarly reduce postprandial inflammation and both alter the gut microbiota of healthy, young men. British Journal of Nutrition, 117 (9), $1312-1322$.

Capitani, C., Hauschild, F. A. D., Friedrich, C. J., Lehn, D. N \& Souza, C. F.V. (2014). Caracterização de iogurtes elaborados com probióticos e fibras solúveis. Revista Brasileira de Tecnologia Agroindustrial. 08(02), 1285-1300.

Cavalcanti, M. S. (2016). Elaboração e Caracterização de Leite Fermentado Caprino "Tipo Iogurte” Sabor Goiaba Com Potencial Probiótico. (Dissertação de Mestrado).Universidade Federal da Paraíba. Programa de Pós-Graduação em Ciência e Tecnologia de Alimentos João Pessoa, PB.

Coimbra de Sá, N., Salvador, S. E. M. \& Silva, B. A. D. A. (2015). Cultura da uva e do vale do São Francisco. RDE-Revista de desenvolvimento Econômico. Edição especial - Salvador, BA, 461- 475.

Cohen, K. O., Matta, V. M., Furtado, A. A. L., Medeiros, N. L. \& Chisté, R. C (2011). Contaminantes microbiológicos em polpas de açaí comercializadas na cidade de Belém-PA. Revista Brasileira de Tecnologia Agroindustrial. 5(2), 524-30.

Franco, B. D. G. M \& Landgraf, M (2005). Microbiologia dos alimentos. Atheneu, 196 p.

Hardy, H. et al. (2013). Probiotics, prebiotics and immunomodulation of gut mucosal defences: homeostasis and immunopathology. Nutrients, 5 (6), 18691912.

Ial. (2008). Normas analíticas do IAL: métodos químicos e físicos para análise de alimentos. 5.ed. Instituto Adolfo Lutz. São Paulo, Brasil.

Lee, W. J. \& Lucey, J. (2010). Formation and physical properties of yogurt. Journal of Animal Science. 23(9), 1127-1136.

Lima, A. R. C. (2011). Avaliação sensorial, química e microbiológica de bebidas lácteas fermentadas elaboradas com polpas de frutas tropicais. (Dissertação Mestrado). Universidade Federal da Paraíba. Programa de Pós-Graduação em Ciência e Tecnologia de Alimentos. João Pessoa, PB.

Matsumoto, M. et al. (2012) Promotion of intestinal peristalsis by Bifido bacterium spp. Capable of hydrolysing sennosides in mice. PloS one, 7(2), 31700 .

Morais, J. L (2017). Desenvolvimento de iogurte caprino com potencial probiótico: características tecnológicas e avaliação do efeito protetor da matriz alimentar. (Dissertação de Mestrado). Universidade Federal da Paraíba. Programa de Pós-Graduação em Ciência e Tecnologia de Alimentos. João Pessoa PB.

Mundim, S. A. P. (2008). Elaboração de iogurte funcional com leite de cabra, saborizado com frutos do cerrado e suplementado com inulina. (Dissertação de Mestrado) Universidade Federal do Rio de Janeiro. Pós-Graduação em Tecnologia de Processos Químicos e Bioquímicos. Rio de Janeiro, RJ.

Nóbrega. J. P. M. et al. (2020). Caracterização física e físico - química de iogurte caprino prebiótico adicionado de geleia de madacaru e maracujá. Reseach Society and development, 9(6).

Ordóñez, J. A. et al. (2005). Tecnologia de alimentos: alimentos de origem animal. (2a ed.), Artmed 280p.

Paiva, Y. F., Deodato, J. N. V., Silva, E. E. V., Silva, E. V., \& Araújo, A. S. (2015). Iogurte adicionado de polpa de abacaxi, base mel: Elaboração perfil microbiológico e físico - química. Revista verde agroecológica e desenvolvimento sustentável. Edição Especial. 22 - 26.

Palanca, V., Rodríguez, E., Señoráns, J. \& Reglero, G (2006). Bases científicas para el desarollo de protuctos cárnicos funcionales com actividad biológica combinada. Nutrición Hospitalaria, Madrid, 21(2), 199-202.

Riener, J., Noci, F., Cronin, D. A., Morgan, D. J., \& Lyng, J. G. (2010). A comparison of selected quality characteristics of yoghurts prepared from thermosonicated and conventionally heated milks. Food Chemistry, 119 (3), 1108-1113.

Ribeiro, M. C. E. (2011). Produção e caracterização de iogurte probiótico batido adicionado de Lactobacillus acidophilus livre e encapsulado. (Dissertação de Mestrado). Universidade Estadual de Campinas. Pós-Graduação em Tecnologia dos Alimentos Campinas, SP.

Rockenbach, I. I. (2008). Compostos fenólicos, ácidos graxos e capacidade antioxidante do bagaço da vinificação de uvas tintas (Vitis vinifera L. e Vitis labrusca L.). (Dissertação de Mestrado). Universidade Federal de Santa Catarina. Pós-Graduação em Ciência dos Alimentos.

SAS. (1999). SAS/STAT user's guide. Version 8, Vol. 2. Cary, N.C., USA, SAS Publishing, 634 p

Saint-Eve, A., Leclercq, H., Berthelo, S., Saulnier, B., Oettgen, W. \& Delarue, J. (2016). How much sugar do consumers add to plain yogurts? Insights from a study examining French consumer behavior and self-reported habits. Appetite, 99, 277- 284.

Santos, M. J. A. (2017). Desenvolvimento, caracterização físico-química e sensorial de iogurte caprino probiótico adicionado de géleia de acerola (Malpighia emarginata). 2017. (Trabalho de Conclusão de Curso). Universidade Federal de Campina Grande. Cuité, PB. 
Research, Society and Development, v. 10, n. 5, e43010514975, 2021

(CC BY 4.0) | ISSN 2525-3409 | DOI: http://dx.doi.org/10.33448/rsd-v10i5.14975

Silva, L. C, Machado, T. B, Silveira, M. L. R, Rosa, C. S \& Bertagnolli, S. M. M. (2012). Aspectos microbiológicos, pH e a acidez de iogurtes de produção caseira comparados aos industrializados da região de Santa Maria - RS. Revista Disciplinarum Scientia (RDS). Serie: Ciência da Saúde, 13(1), 111- 120.

Silva, M. L. T, Brinques, G. B, Gurak, P. D. (2019). Utilização de farinha de subproduto de brotos para elaboração de massa alimentícia fresca. Brazilian Journal Food Technology. 22. e2018063.

Soares. D. S. (2008). Desenvolvimento de formulação para produção de iogurte á base de soro de leite. (Dissertação de Mestrado). Universidade Federal de Pernambuco. Programa de Pós-Graduação em Nutrição. Recife, PE.

Stencl, J., Janstova. B., \& Drackova, M. (2010). Effects of temperature and water activity on the sorption heat of whey and yogurt powder spray within the temperature range 20-40c. Journal of Food Process Engineering, 33, (5), 946 - 961.

Tamine, A. Y. et al. (2011). Review Popular ovine and caprine fermented milks. Small Ruminant Research, 101(1-3), 2-16.

Xanthopoulos, V., Ipsilandis, C. G., \& Tzanetakis, N. (2012). Use of a selected multi-strain potential probiotic culture for the manufacture of set-type yogurt from caprine milk. Small Ruminant Research, 106(2), 145-153.

Zeković, D. B., Kwiatkowski, S., Vrvić, M. M., Jakovljević, D. \& Moran, C. A. (2005). Natural and modified (1 $\rightarrow$ 3)- $\beta$-D-glucans in health promotion and disease alleviation. Critical reviews in biotechnology, 25(4), 205-230. 